\title{
A Simulation of Four Stroke Marine Diesel Engines to Predict Internal Cylinder Characteristics
}

Mô hình động cơ diesel tàu thủy bốn kỳ để dự đoán các đặc tính bên trong xy lanh

\author{
Nguyen Quang Vinh ${ }^{*}$, Le Van Vang ${ }^{2}$, Bui Hong Duong ${ }^{2}$ \\ ${ }^{I}$ Naval Technical College, Ho Chi Minh City, Vietnam \\ ${ }^{2}$ Ho Chi Minh City University of Transport, Ho Chi Minh City, Viet Nam \\ *Email: quangvinh2802@gmail.com
}

\begin{abstract}
This paper introduces a simulation of four-stroke marine diesel engines. The submodel of a particular cylinder was carried out, based on the first law of thermodynamics, programmed by Matlab/Simulink program, which describes the relations among internal characteristics, including cylinder performance parameters, heat release, heat loss, and pressure. The heat release is based on the Wiebe function and the heat loss is based on the Woschni function to build submodels. From the result of the model, the indicated pressure of a single cylinder was taken, the brake power of the engine could be estimated through this pressure. The object of the simulation is a new engine, hence the technical documents and test records provided by the manufacturer are sufficient. The model got the input parameters from this and the key outputs of the model (for example the brake power, peak combustion pressure, specific fuel consumption) were compared with the test records to adjust and make it more accurate. These gaps were not over $5 \%$, therefore, this model can be used to predict key complicated internal cylinder characteristics, for example, the pressure, temperature, and thermal efficiency of engines.
\end{abstract}

Keywords: Diesel engine simulation, heat release; heat loss, indicated pressure, brake power.

Tóm tắt

Bài báo trình bày một mô hình mô phỏng động cơ diesel tàu thủy 4 kỳ. Mô hình được xây dựng dựa trên định luật nhiệt động thư nhất, và được lập trình bằng Matlab/Simulink, trong đó mô tả các đặc tính bên trong bao gồm: các đặc tính động học, đặc tính phát nhiệt, tổn thất nhiệt và đặc tính áp suất. Quá trình phát nhiệt mô phỏng dựa trên phương trình Wiebe, tốc độ truyền nhiệt dựa trên phương trình Woschni. Từ kết quả của mô phỏng, áp suất chỉ thị trong xy lanh xác định và công suất có ích cũng được tính toán qua kết quả mô phỏng. Đối tượng của nghiên cứu là động cơ mới, vì vậy các số liệu từ hồ sơ kỹ thuật được cung cấp bởi các nhà sản xuất sẽ rất hữu ích để đánh giá kết quả mô phỏng. Các thông số đầu vào được lẩy từ các tài liệu này, các kết quả đầu ra mô phỏng (công suất, áp suất cực đại, suất tiêu hao nhiên liệu) được so sánh với kết quả thử nghiệm tại nhà máy sản xuất để hiệu chỉnh và nâng cao độ chính xác của mô phỏng. Các sai lệch không vượt quá $5 \%$, vì vậy có thể dùng mô hình mô phỏng để dự đoán những đặc tính kỹ thuật bên trong xy lanh, như áp suất chỉ thị, nhiệt độ, và hiệu suất nhiệt của động cơ'

Từ khóa: Mô phỏng động cơ diesel, phát nhiệt, tổn thất nhiệt, áp suất chỉ thị, công suất.

\section{Introduction}

The diesel engine is still the main choice for marine propulsion due to its power and efficiency. Improving efficiency and reducing emissions are necessary requirements now. Building a simulation which represents the working process of a diesel engine is one of the methods used to study real engines.

There are many simulations that are based on a kinetic, dynamic, heat balancing, mass balance model, etc. The mathematical differential equations have been used to simulate the working process of diesel engines. These equations then were especially solved by a programming language with the computer, and the

ISSN 2734-9381

https://doi.org/10.51316/jst.154.etsd.2021.31.5.3

Received: December 10, 2017; accepted: September 22, 2021 results with graphics could describe the characteristic of parameters varying the crank angle (CA). Weibe function, named after a Russian engineer Ivan Weibe, is the best-known technique for solving the burn rate and heat release inside the cylinder [1]. For computing heat transfer, Woschni developed the formulas which were developed and largely applied [2].

R.S.Benson and N.D.Whitehouse, in their book, analyzed heat release, heat transfer and friction [3] they also built program codes with Fortran language which applied for Otto cycle engines and dual combustion cycle engines. John Heywood in his book [4] has presented some key methods, including QuasiSteady flow, filling and emptying, gas dynamic 
method, which are the basis to build many models on. Miyamoto et al [5] developed a real diesel model with six parameters of the combustion process which combined theories and experiments to determined them and their relations. Colin R.Ferguson and Allan T.Kirkpatrick in their research [6] based on the mean value engine model and thermodynamic laws created models of the internal combustion engine and the simple simulations showed results with high reliability. Lars Erikson and Lars Nielsen presented a method of building a complete model of an automotive turbocharged engine, including main components: turbocharger, inlet and exhaust manifolds, cylinder and their relationships [7]. Maftei et al [8] built a model of the dynamics of a marine diesel engine based on the cylinders sequence and the help of the State Flow toolbox in Matlab computing environment, the results were used to predict the behaviour of the propulsion plant.

The aim of this simulation is to build a working process simulation code for predicting what happens inside cylinders. The mean value engine model (MVEM) has been used in this simulation due to the simplicity and affordable results. Runge-Kutta algorithm was used to solve the differential equations. The object of the study is to build a simulation model of the new engine; therefore, the initial parameters (intake pressure, intake temperature) were taken from engine documents and test records provided by the manufacturer. The key outputs of simulation (brake power, peak pressure, and specific fuel consumption) were compared with engine specifications, the gaps were not over $2 \%$ between them. The results of the simulation gave us the accurate characteristics of the internal cylinder.

\section{Model Structure}

\subsection{Engine Performance Parameters}

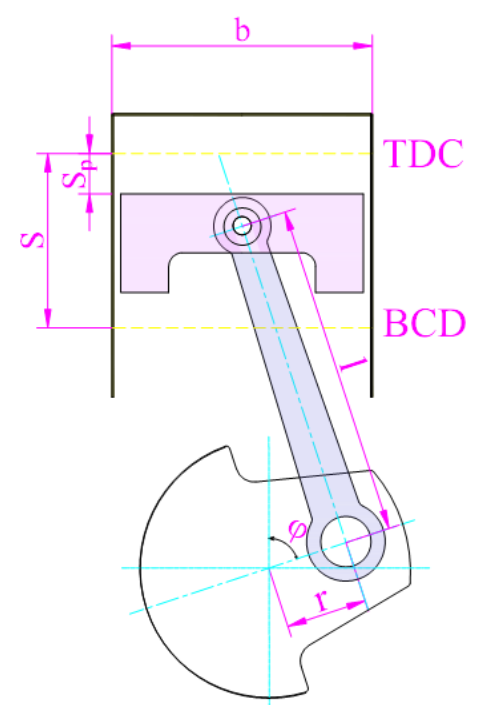

Fig. 1. Engine performance
Fig. 1 describes the piston movement in the cylinder following engine crank angle, assuming that crank angle (CA) $\varphi=0$ when the piston at the top dead centre (TDC), the dimensionless instantaneous stroke is:

$$
\bar{s}_{p}=\frac{s_{p}}{s}=\frac{1}{2}(1-\cos \varphi)+\frac{1}{2 e}\left[1-\left(1-e^{2} \sin ^{2} \varphi\right)^{1 / 2}\right](1)
$$

where $s$ is the distance between the top dead centre (TDC) and bottom dead centre (BDC); $s_{p}$ is the instantaneous stroke, $e$ is the ratio of the crankshaft radius $r$ to the connecting rod length $l, e=r / l$.

The Instantaneous volume displacement $V_{d}(\varphi)$ is:

$$
V_{d}(\varphi)=\pi \cdot b^{2} \cdot s_{p} / 4
$$

Dimensionless instantaneous cylinder volume:

$$
\bar{V}_{d}=\frac{V_{d}(\varphi)}{V_{a}}=\frac{1}{e}\left[1+\frac{\varepsilon-1}{2}(1-\cos \varphi)+\frac{1}{2 e}\left[1-\left(1-e^{2} \sin ^{2} \varphi\right)^{1 / 2}\right]\right]
$$

where $V_{a}$ is cylinder volume when piston at BDC, $\varepsilon$ is the compression ratio; $e$ is the ratio of the crankshaft radius $r$ to the connecting rod length $1, e=r / l$.

\subsection{Heat Release}

The total low heat value $L H V(\mathrm{~kJ} / \mathrm{kg})$, which provide for a cycle, is calculated as

$$
Q_{i n}=\frac{L H V^{*} m_{\text {air }}}{A F R}
$$

where $L H V$ is low heat value of fuel $(\mathrm{kJ} / \mathrm{kg}), m_{\text {air }}$ is the amount of air in a cycle, $A F R$ is the air/fuel ratio.

The increment heat $\partial Q_{i n}$ is calculated as:

$$
\frac{\partial Q_{i n}}{d \varphi}=Q_{i n} \frac{d \mathrm{x}}{d \varphi}
$$

where the cumulative burn fraction of fuel $(x)$ is based on double Weibe's formula $[1,5]$

$$
\begin{aligned}
& \frac{d x}{d \varphi}=\frac{d x_{1}}{d \varphi}+\frac{d x_{2}}{d \varphi} \\
& \frac{d x_{1}}{d \varphi}=\beta \cdot a\left(m_{p}+1\right) \frac{1}{\varphi_{p}}\left(\frac{\varphi-\varphi_{s}}{\varphi_{p}}\right)^{-a\left(\frac{\varphi-\varphi_{s}}{\varphi_{p}}\right)^{m_{p}+1}} \\
& \frac{d x_{2}}{d \varphi}=(1-\beta) \cdot a\left(m_{d}+1\right) \frac{1}{\varphi_{d}}\left(\frac{\varphi-\varphi_{s}}{\varphi_{d}}\right){ }^{-a\left(\frac{\varphi-\varphi_{s}}{\varphi_{d}}\right)^{m_{p}+1}}
\end{aligned}
$$

where $d x / d \varphi$ is the combustion law; $d x_{1} / d \varphi$ is the premix combustion law; $d x_{2} / d \varphi$ is the diffusion combustion law; $a$ is the Weibe efficiency factor; $m_{p}$ is the premix combustion quality factor; $m_{d}$ is the diffusion combustion quality factor; $\varphi_{\mathrm{s}}$ is the start of combustion; $\varphi_{p}$ is the duration of premix combustion; 
$\varphi_{d}$ is the duration of diffusion combustion; $\beta$ is the ratio of the amount of fuel burning in premix combustion phase to the total. Tuning burning parameters are Weibe factors which were estimated by the mean pressure as the research of Miyamoto [5].

\subsection{Heat Loss}

The heat transfer through the surrounded wall of combustion chamber $\partial \mathrm{Q}_{\text {loss }}$ is calculated as [6]:

$$
\frac{\partial Q_{\text {loss }}}{d \varphi}=h_{g}(\varphi) A_{w}(\varphi)\left(T-T_{w}\right) / n_{e}
$$

where $T(\mathrm{~K})$ is the instantaneous bulk gas temperature; $T_{w}$ (K)is the mean temperature of cylinder wall; $A_{w}(\varphi)\left(\mathrm{m}^{3}\right)$ is the area of combustion chamber surface, $n_{e}$ is the engine speed (rev/min); and $h_{g}\left(\mathrm{~W} / \mathrm{m}^{2} . \mathrm{K}\right)$ is the Woschni heat transfer coefficient which is calculated as follows:

$$
h_{g}=3,26 p^{0.8} U^{0.8} b^{-0.2} T^{-0.55}
$$

where $b(\mathrm{~m})$ is the cylinder bore; $U(\mathrm{~m} / \mathrm{s})$ is the heat transfer rate which follows Woschni's equation:

$$
U=2.28 \bar{v}_{p}+0.00324 \frac{V_{d} T_{a}}{p_{a} V_{a}} p
$$

where $T_{a}(\mathrm{~K})$ and $p_{a}\left(\mathrm{~N} / \mathrm{m}^{2}\right)$ are the temperature and pressure at the end of the charging process, respectively. $\overline{\mathrm{v}}_{\mathrm{p}}$ is mean piston speed $(\mathrm{m} / \mathrm{s}), V_{d}\left(\mathrm{~m}^{3}\right)$ is the displacement volume, $V_{a}\left(\mathrm{~m}^{3}\right)$ is cylinder volume when piston at BDC.

\subsection{The First Law of Thermodynamics}

Building a simulation of the process of a diesel engine is certainly a complicated job. In this paper, the First law of Thermodynamics is used to build this model, with the assumption that the intake and the exhaust processes are of isentropic processes and the exhaust gas is expelled to a constant pressure chamber. The compression, combustion and expansion processes include the processes of heat release, heat transfer as shown in the following heat balance differential equation:

$$
\frac{\partial Q_{i n}}{d \varphi}-\frac{\partial Q_{\text {loss }}}{d \varphi}-p \frac{d V}{d \varphi}=m c_{v} \frac{d T}{d \varphi}+c_{v} T \frac{d m}{d \varphi}
$$

where $c_{v}$ is constant volume specific heat $(\mathrm{J} / \mathrm{kg} . \mathrm{K})$.

From the equation of state $p V=m R T$, which in differential form is:

$$
m d T=\frac{1}{R}(p d V+V d p)
$$

To combine equation (13) with equation (14), the differential equation of cylinder pressure varying with the crank angle (CA) is written as follows:

$$
\frac{d p}{d \varphi}=-k \frac{p}{V} \frac{\mathrm{d} V}{d \varphi}+\frac{k-1}{V} \frac{\partial \mathrm{Q}_{\text {in }}}{d \varphi}-\frac{k-1}{V} \frac{\partial \mathrm{Q}_{\text {loss }}}{d \varphi}
$$

where $k(-)$ is the gas constant $\left(c_{p} / c_{v}\right)$.

\section{Case Study}

The flow diagram used to compute the gas pressure that is built up in a working cylinder chamber at a working cycle to compute the power of the engine is shown in Fig. 2. The particular submodel and respective model in Simulink are shown in Fig. 3, The sample diesel engine is a 6N18AL one, by Yanmar, Japan. Key engine parameters as in Table 1.

Table 1. Key engine parameters (Operation in ISO conditions)

\begin{tabular}{|l|c|}
\hline \multicolumn{1}{|c|}{ Diesel engine 6N18AL } & Parameters \\
\hline Numbers of cylinder & 6 \\
\hline Cylinder bore $(\mathrm{mm})$ & 180 \\
\hline Stroke $(\mathrm{mm})$ & 280 \\
\hline Compression ratio & 16.5 \\
\hline Nominal speed (rpm) & 900 \\
\hline Nominal brake power $(\mathrm{kW})$ & 480 \\
\hline Start of injection $\left({ }^{\circ} \mathrm{CA}\right)$ & 8 \\
\hline Firing order & $1-4-2-6-3-5$ \\
\hline Specific fuel consumption, $\mathrm{g} / \mathrm{kWh}$ & 195 \\
\hline
\end{tabular}

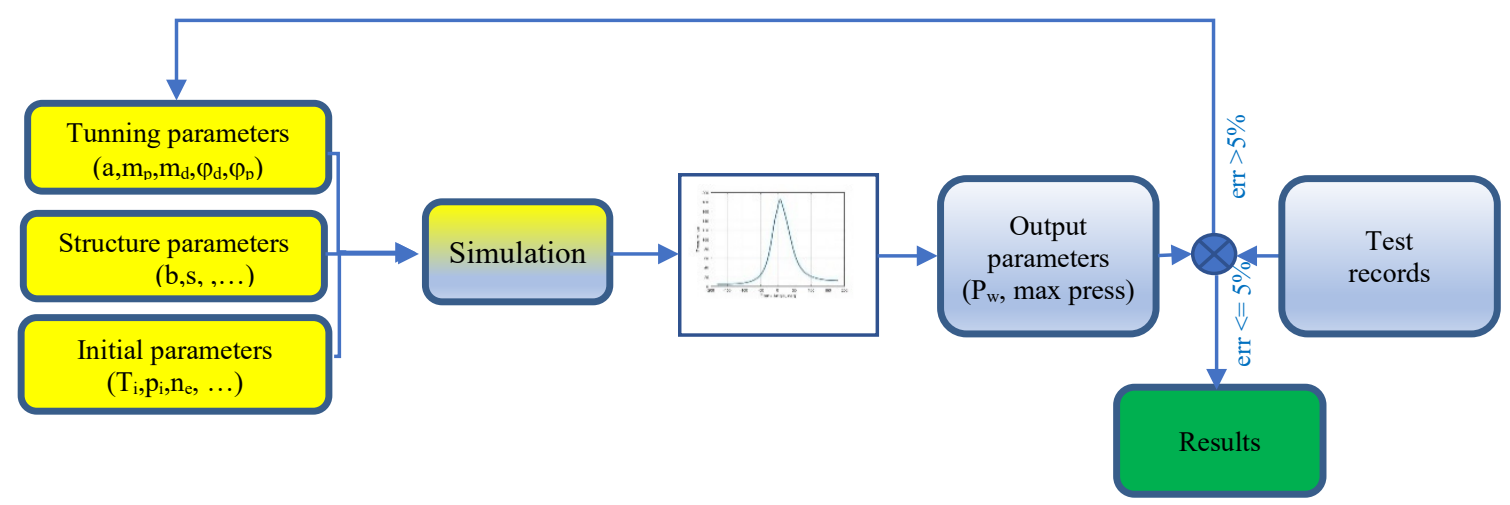

Fig. 2. Flow diagram for simulation 


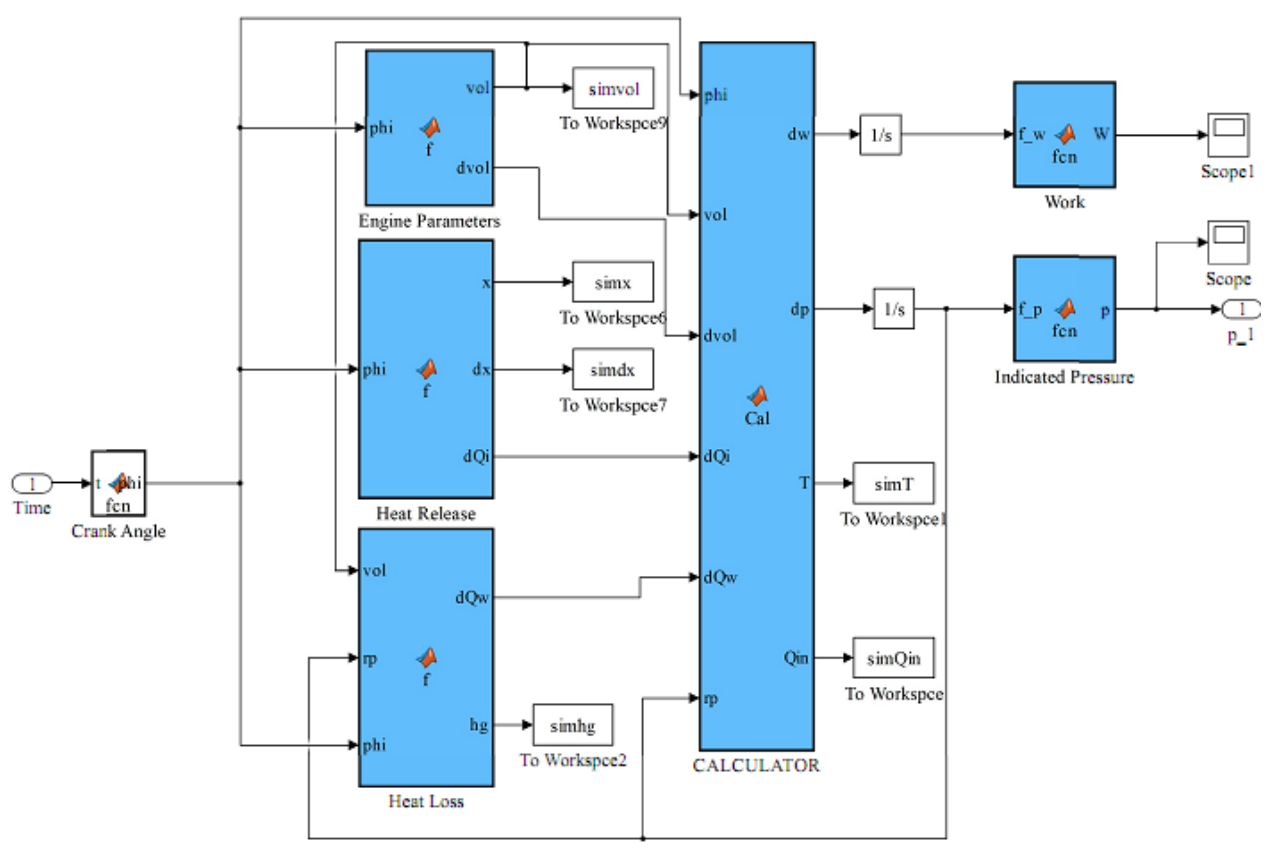

Fig. 3. Simulink model of a particular cylinder

\subsection{Calculating flow diagram}

Fig. 2 presents a flow diagram which used to program the engine thermodynamic simulation

The structure parameters such as bore cylinder, piston stroke, compression ratio... are taken from engine specifications, which are fixed.

The initial parameters: intake temperature $\left(T_{i n}\right)$, intake pressure $\left(p_{i n}\right)$, engine speed $\left(n_{\mathrm{e}}\right)$, and the start of injection $(S O I)$. These values are taken from the test records provided by the manufacturer.

The value of the tuning parameters: the Weibe's function parameters $\left(a, m_{p}, m_{d}, \varphi_{p}, \varphi_{d}\right)$, which are tuned by the description of [5] firstly and step by step (automatic) were corrected via a feed-back loop in the model.

\subsection{Simulink Model for a Particular Cylinder}

Based on above theories, a Simulink model was established to describe internal component relationships of a particular cylinder (Fig. 3). Engine parameters block based on (1)-(3), Heat Release block based on (4)-(8), Heat loss block based on (9)-(11), Calculator block based on (12)-(14), Work block and Indicated Pressure block based on (15)-(19)

\subsection{Indicated Pressure and Brake Power}

The result from the model, the indicated pressure $p_{c y l}$ varying according to crank angle is characterized. Based on this, the indicated work $W_{i}$ (the work that is produced per cycle in each cylinder) is calculated as:

$$
W_{i}=\int p_{c y l} d V
$$

Indicated power is defined as the power developed by combustion of fuel inside the engine cylinder. The indicated power is calculated through the indicated work and numbers of cylinder.

$$
P_{i}=i \cdot W_{i} \cdot n_{e} / 120
$$

where $i$ is the number of cylinders; $n_{e}$ is the engine speed (rpm)

Brake Power output, $P_{w}$, is the rate which work is done; therefore, it is the output power. The brake power output equation is

$$
P_{b}=P_{i}-P_{f}
$$

where $P_{f}$ is the friction power (loss power). Mean fiction pressure, $M F P$, can be modeled according to Eriksson and Nielsen [7]

$$
M F P=C_{f 0}+C_{f 1}\left(\frac{60 n}{1000}\right)+C_{f 2}\left(\frac{60 n}{1000}\right)^{2}
$$

where $C_{f o}, C_{f 1}, C_{f 2}$ are tuning parameters.

Therefore, the friction power $P_{f}$ is

$$
P_{f}=i . M F P . V_{d} \cdot n_{e} / 2
$$

where $V_{d}$ is displacement volume $\left(\mathrm{m}^{3}\right), n_{e}$ is the engine speed (rpm); $i$ is the number of cylinders

Key engine output parameters of model and the comparison with test records are given as follows. From the simulation, key engine output parameters are presented as in Table 2.

Output parameters are peak combustion pressure $\left(p_{z}\right)$, brake power $\left(P_{w}\right)$, and specific fuel consumption 
$\left(g_{e}\right)$. The output parameters were taken from the simulation and standard values (from test records).

These errors in Table 2 are not over $5 \%$, therefore the modeling of the engine can be accepted and using it for presentation of internal characteristics inside the cylinder as in the following part.

Table 2. Comparing output parameters of simulation and test records

\begin{tabular}{|l|c|c|c|}
\hline Key parameters & Simulation & $\begin{array}{c}\text { Test } \\
\text { records }\end{array}$ & Errors, \% \\
\hline $\begin{array}{l}\text { Max. combustion } \\
\text { pressure, bar }\end{array}$ & 133.5 & 132 & 0.34 \\
\hline Brake power, kW & 475.5 & 480 & 0.92 \\
\hline $\begin{array}{l}\text { Specific fuel } \\
\text { consumption, } \\
\text { g/kWh }\end{array}$ & 198 & 195 & 1.6 \\
\hline
\end{tabular}

\section{The Predictions and Discussions}

\subsection{Variation of Piston Velocity and Volume}

Piston motion produces the engine power output

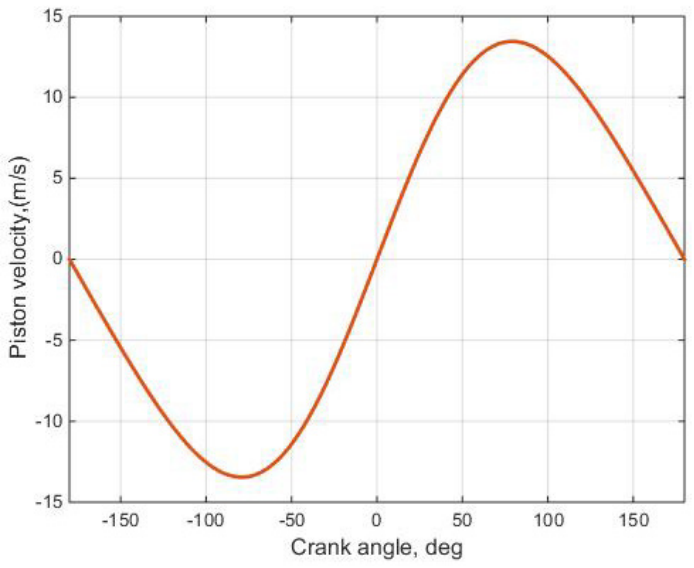

Fig. 4. Piston velocity $(\mathrm{m} / \mathrm{s})$ varies with CA (deg)

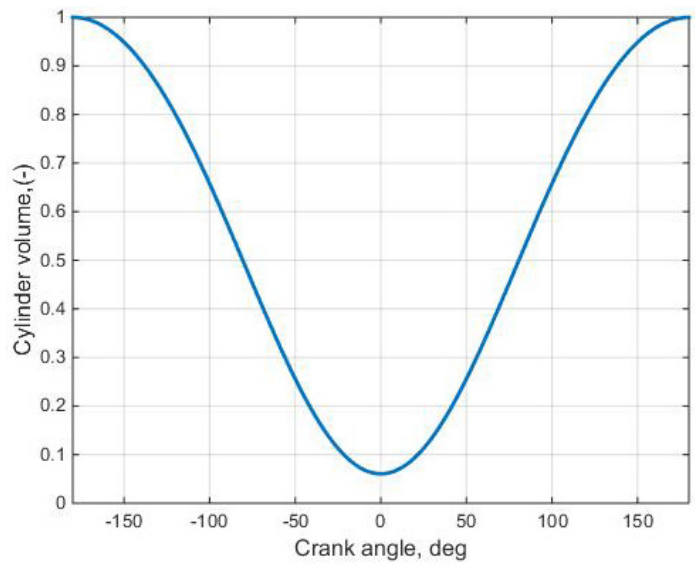

Fig. 6. Dimensionless cylinder volume (V/Va) varies with CA (deg) and thus inside characteristics of mixture gas flow are varied. Fig. 4 presents piston velocity following crank angle. The piston velocity is negative at compression stroke $\left(-180^{\circ}-0^{\circ}\right.$ crank angle), equals zero at TDC $\left(0^{\circ} \mathrm{CA}\right)$, positive at expansion stroke $\left(0^{\circ}-180^{\circ}\right)$

According to (3), the dimensionless cylinder volume $(\mathrm{V} / \mathrm{Va})$ was presented following crank angle as below Fig. 5.

\subsection{The Cumulative and the Rate of Energy Release for a Combustion}

The variation of burn fraction and energy release are presented in Fig. 6 and Fig. 7.

The cumulative energy release is presented in Fig. 6, the curve begins at the start of injection SOI, according to engine specifications $S O I=80$ (before TDC). The start of combustion $S O C$ was calculated through ignition delay time $\tau_{i d}$, in crank angle degrees, (the period as the crank angle between SOI and SOC) is calculated as $[4,6,9]$ :

$$
\tau_{i d}=\left(0.36+0.22 v_{p}\right) e^{E_{a}\left(\frac{1}{R T}-\frac{1}{17,190}\right)\left(\frac{21.2}{p-12.4}\right)^{0.63}}
$$

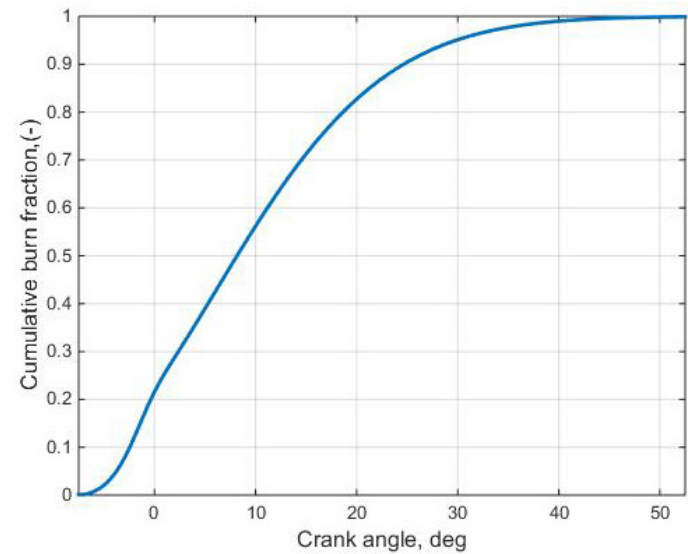

Fig. 5. Variation cumulative burn fraction (x) with CA (deg)

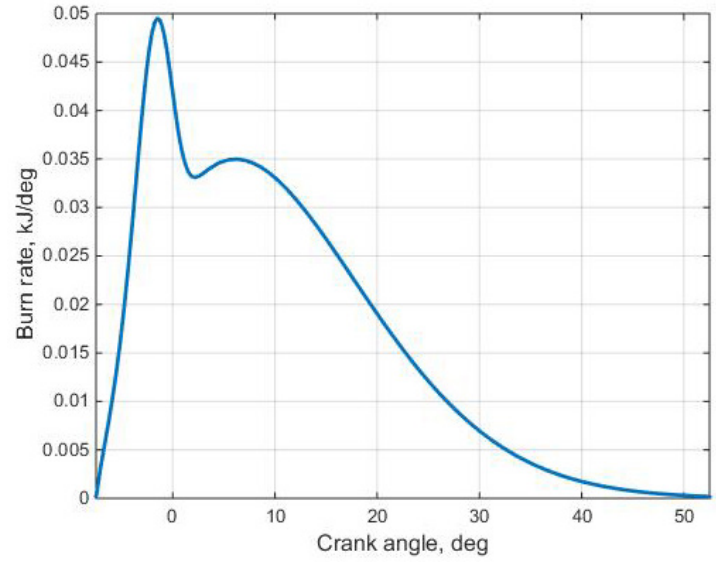

Fig. 7. Variation rate of energy release $(\mathrm{dx} / \mathrm{d} \varphi)$ with CA (deg) 

$\mathrm{J} / \mathrm{mole}$

The term $E_{a}$ is the apparent activation energy in

$$
E_{a}=\frac{618,840}{C N+25}
$$

where, $v_{p}(\mathrm{~m} / \mathrm{s})$ is the mean of piston velocity, $R(\mathrm{~J} / \mathrm{kg} . \mathrm{K})$ is the universal gas constant, $T(\mathrm{~K}), p$ (bar) is the temperature and pressure at $S O I, C N$ is the Cetane number.

The rate of energy release is presented in Fig. 7. Satisfied with the theory [4], the diesel engine combustion has two behaviour stages (premixed and diffusive combustion) and each of them has two peaks of burn rate. These results are well and conveniently approximated by the double Wiebe function [5].

\subsection{Variation of Heat Fluxes and In-Cylinder Temperatures Variation Follows Crank Angle.}

There is a wide range of temperatures and heat fluxes throughout an internal combustion engine. The value of heat flux depends on the crank angle (Fig. 8), the sources of heat flux are not only combustion gases, but also the friction which occurs between moving surfaces. The temperature of the mixed gas is presented in Fig. 9

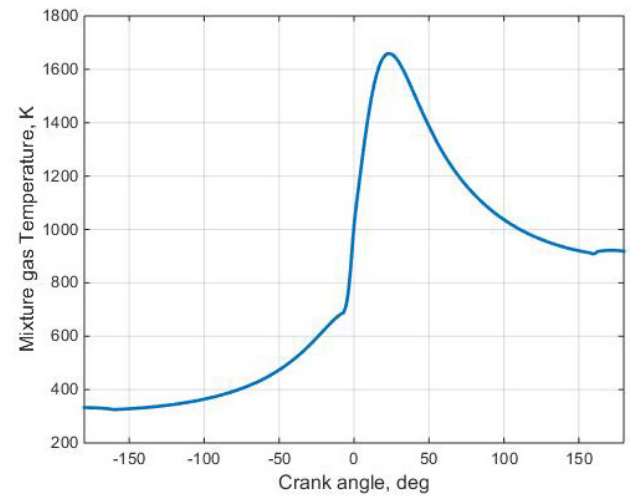

Fig. 9. In-cylinder temperature with CA (deg)

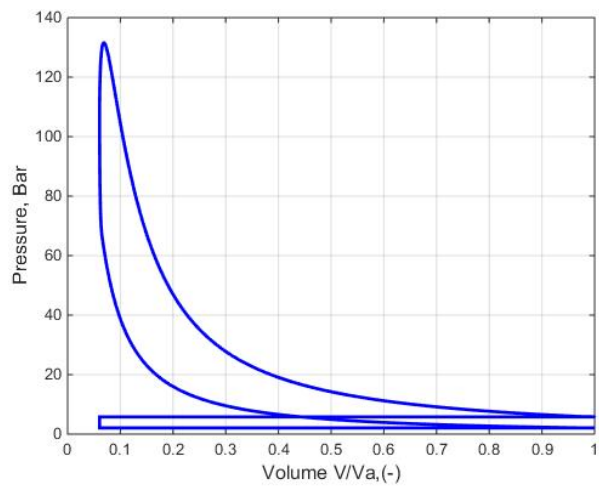

Fig. 11. p - V Diagram

\subsection{Variation of In-Cylinder Pressure Variation Follows Cylinder Volume and Crank Angle.}

Fig. 10 presents the in-cylinder pressure variation following cylinder volume (dimensionless, $V / V_{a}$ ). The in-cylinder pressure variation with crank angle is presented in Fig. 11.

\subsection{The Cumulative Heat Loss and Cumulative Work}

The cumulative work and heat loss are plotted in Fig. 12. The cumulative work is initially negative due to the piston moving up (compression stroke) and becomes positive in expansion stroke.

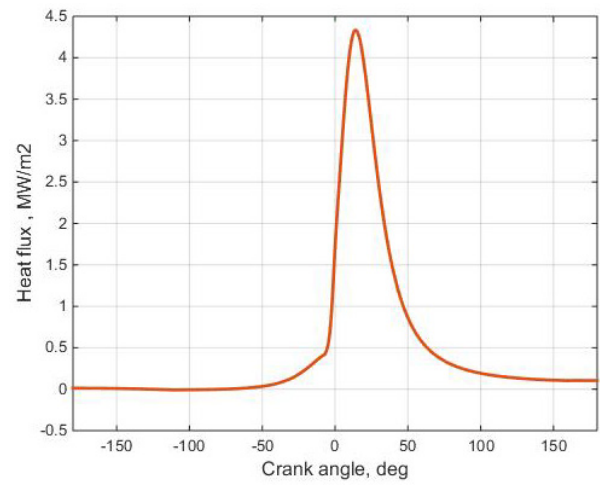

Fig. 8. Heat flux with CA (deg)

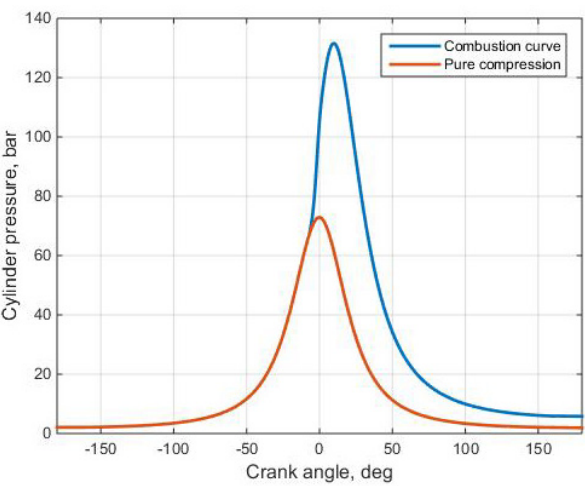

Fig. 10. In - cylinder pressure with crank angle

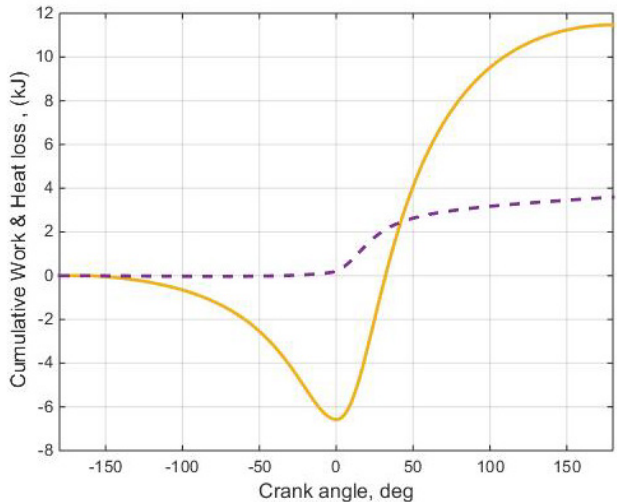

Fig. 12. Cumulative Work and Heat loss (kJ) with CA (deg) 


\section{Conclusion}

The research has gained some results:

We built a simulink model of a diesel engine that can describe their characteristics and relations among factorials (heat release, heat loss, work). The inputs of the model are the same as in engine technical documents, the outputs are compared with test records (provided by the manufacturer) to evaluate its accuracy.

Based on the model, the predictions of internal characteristics were presented including cumulative energy release curve, rate of energy release curve, temperature, heat flux, pressure, cumulative work, and heat transfer. The engine power output, efficiency, fuel specific consumption can also be displayed.

In this modeling, we only focused on the cylinder, the intake temperature and pressure (before the cylinder) were taken from test records, and therefore this ignored the turbocharger. However, this model is helpful for training courses of this engine and the simulation can be used for studying other kinds of engine based on their documents.

\section{References}

[1] Weibe, I., Semi-empirical expression for combustion rate in engines, in Proceedings of Conference on Piston Engines, USSR Academy of sciences, Moscow. 1956, USSR Academy of sciences, Moscow. p. 185-191.

[2] Woschni, Gerhard. A universally applicable equation for the instantaneous heat transfer coefficient in the internal combustion engine, No. 670931, SAE Technical Paper, 1967.

https://doi.org/10.4271/670931

[3] Benson, R.S. and N.D. Whitehouse, Internal Combustion Engines. 1984: Elsevier Science \& Technology Books.

[4] Heywood, John B., Internal combustion engine fundamentals, McGraw-Hill Education, 2018.

[5] Miyamoto, Noboru, et al., Description and analysis of diesel engine rate of combustion and performance using Wiebe's functions, SAE Transactions (1985): 622-633. https://doi.org/10.4271/850107

[6] Ferguson, C.R. and A.T. Kirkpatrick, Internal combustion engines: applied thermosciences. 2015: John Wiley \& Sons.

[7] Eriksson, L. and L. Nielsen, Modeling and control of engines and drivelines. 2014: John Wiley \& Sons.

https://doi.org/10.1002/9781118536186

[8] Maftei, C., L. Moreira, and C.G. Soares, Simulation of the dynamics of a marine diesel engine. Journal of Marine Engineering \& Technology, 2009. 8 (3), pp. 29-43. https://doi.org/10.1080/20464177.2009.11020225

[9] Hardenberg, H. O., and F. W. Hase., An empirical formula for computing the pressure rise delay of a fuel from its cetane number and from the relevant parameters of direct-injection diesel engines, SAE Transactions (1979), 1823-1834. https://doi.org/10.4271/790493 